\title{
- Tanatologia : fenômenos cadavéricos abióticos
}

\section{- Tanathology : abiotical cadaveric phenomenons}

\author{
Enio Pedone Bandarra-CRMV-SPn ${ }^{0} 0786$ \\ Júlio Lopes Sequeira-CRMV-SP nº 3572
}

Laboratório de
Patologia e Medicina
Legal Veterinária
Departamento de
Clínica Veterinária
Faculdade de Medicina
Veterinária e Zootecnia
de Botucatu - UNESP
18618-000 - Botucatu,
São Paulo. Fone: (014)
820.6283
Email:
bandarraep@fmvz.unesp.br

\section{RESUMO}

Apresenta-se a primeira parte de uma revisão sobre Tanatologia onde são abordados os fenômenos cadavéricos abióticos, destacando-se a importância do conhecimento de cada um deles na interpretação dos achados de necrópsia e sua utilidade na determinação aproximada do tempo decorrido após o óbito.

Unitermos: Tanatologia, Fenômenos cadavéricos, Medicina legal veterinária

1 anatologia é o ramo da Patologia que estuda a morte, conhecimento de fundamental importância para todos aqueles que atuam na defesa da vida, pois é através do exame pós-morte ou necroscopia que é possível a avaliação exata das condições que levaram o animal à perda da condição de higidez e porque muitas vezes, a despeito de todos os esforços médicos, a batalha com a morte foi perdida.

Desta forma é preciso ter-se em mente a possibilidade de se extrair de algo indesejável, desagradável, e por muitas vezes frustrante como a morte, ensinamentos básicos para que a próxima batalha possa ser ganha pela vida.

Para tal, é necessário que seja estabelecido o conceito de morte, e que o conhecimento dos fenômenos cadavéricos seja de domínio daqueles que ao analisar um cadáver pretendem obter o maior número de informações possíveis, independentemente do tempo decorrido após o óbito.

Pode-se portanto conceituar-se morte como a rotura do equilíbrio biológico e físico - químico, fundamen- tais à manutenção da vida, caracterizando-se pela cessação dos fenômenos vitais pela perda das funções cerebral, respiratória e circulatória.

Para se verificar a certeza da morte e evitar que alterações ocorridas após o óbito mascarem ou forneçam informações erradas sobre suas causas é necessária a observação cuidadosa dos fenômenos cadavéricos.

Os fenômenos cadavéricos são classificados em abióticos e transformativos; os primeiros ocorrem sem a interferência de agentes biológicos, enquanto nos transformativos esta interferência é intensa, exceção feita à autólise.

Os abióticos se dividem em imediatos e mediatos ou consecutivos, já os transformativos são classificados em destrutivos e conservadores.

Os Fenômenos Abióticos Imediatos são aqueles que se confundem com o momento da morte, o que alguns autores denominavam no passado como estado metagônico. Deve-se ainda ressaltar que, nos tempos modernos e na medicina humana, a perda das funções cere- 
brais, a chamada morte cerebral é a determinante deste estado.

Os fenômenos cadavéricos abióticos imediatos são: perda da consciência; desaparecimento dos movimentos e do tonus muscular, perda dos movimentos respiratórios e dos batimentos cardíacos, perda da ação reflexa a estímulos táteis, térmicos e dolorosos e perda das funções cerebrais.

Somente o conjunto destes fenômenos caracterizam a morte, uma vez que, isoladamente, com exceção da perda das funções cerebrais, podem ser produzidos ou ocasionados por ação de substâncias químicas ou por vários tipos de processos mórbidos.

Os fenômenos abióticos consecutivos são os seguintes: desidratação, resfriamento do corpo, manchas de hipostase, rigidez cadavérica, coagulação do sangue, alterações oculares e autólise.

Todos eles ocorrem em virtude da parada total das atividades metabólicas do organismo e da prevalência de fenômenos físicos a que estão sujeitos todos os corpos inertes.

Deve-se destacar que as condições em que ocorreu a morte assim como o local da mesma causam, de maneira geral, alterações significativas no desenrolar dos fenômenos cadavéricos, havendo necessidade, portanto, de uma análise criteriosa de todos os dados obtidos para que se possa evitar interpretações errôneas.

\section{Desidratação}

A perda passiva de líquidos corpóreos, também denominada evaporação cadavérica, depende fundamentalmente de fatores ambientais, tais como: temperatura ambiente, presença ou ausência de correntes de ar, intensidade das mesmas, umidade relativa do ar e meio em que se encontra o cadáver. As condições pregressas do animal antes do óbito também exercem papel importante no processo, o que requer um cuidado especial na avaliação correta deste fenômeno, evitando-se erros de interpretação indesejáveis. A desidratação cadavérica é melhor observada nos globos oculares e na perda de elasticidade da pele, devendo-se destacar que em virtude do decúbito do animal o processo ocorrido após a morte não se apresenta de forma uniforme por todo o tegumento.

\section{Resfriamento do cadáver}

Em virtude da ausência de atividade metabólica, um cadáver não produz nem mantém o calor, de forma que a temperatura corpórea tende a se equilibrar com a temperatura ambiente. Esta perda de calor é, em média, de cerca de um grau centígrado por hora.

Alguns fatores influenciam este fenômeno aumentando ou diminuindo este tempo; assim devem ser considerada a espécie e condições do cadáver, pois animais de grande porte tendem a perder calor mais lentamente que os de pequeno porte, da mesma forma os ruminantes não apresentam um resfriamento completo, pois os fenômenos de fermentação relacionados à flora e fauna rumenal continuam por longo tempo. Os animais, que apresentam um panículo adiposo desenvolvido, evidentemente demoram mais tempo a perder calor, enquanto que aqueles que sucumbiram vítimas de um processo mórbido de longa duração o fazem rapidamente.

$\mathrm{O}$ meio ambiente ou o local onde se encontra o cadáver também interfere significativamente; desta forma, quanto mais fria for a temperatura ambiente ou seja, quanto maior for a diferença de temperatura entre o animal e o meio ambiente, mais rapidamente ocorre o resfriamento, da mesma forma um corpo imerso em líquido, pois este é melhor transmissor de calor do que o ar. Devese ressaltar que, em alguns casos de doenças infecciosas como o tétano por exemplo a temperatura post mortem pode elevar-se intensamente, imediatamente após o óbito.

Livores de Hipostase, também denominada lividez cadavérica, se caracteriza pela extrema palidez do cadáver e pelo aparecimento de manchas violáceas nas partes em declive do corpo sendo que, estas últimas costumam aparecer entre uma e duas horas após a morte e ambas devem-se à perda da função circulatória e ação da gravidade fazendo que o sangue se acumule nas porções mais baixas do cadáver.

A observação deste fenômeno em animais é extremamente dificultada pela pigmentação da pele e pelo pelame.

\section{Rigidez cadavérica ou rigor mortis}

A causa principal deste fenômeno é a redução do conteúdo de compostos de fosfato energeticamente ricos (ATP e Creatinina Fosfato) que estimulam a contratura de toda a musculatura do cadáver; surge via de regra entre duas e três horas após a morte, desaparecendo entre 24 e 48 horas depois.

A rigidez cadavérica é um dos fenômenos cadavéricos mais úteis na determinação do tempo da morte, pois se manifesta de uma maneira ordenada; assim se instala inicialmente nos músculos da pálpebra, em segui- 


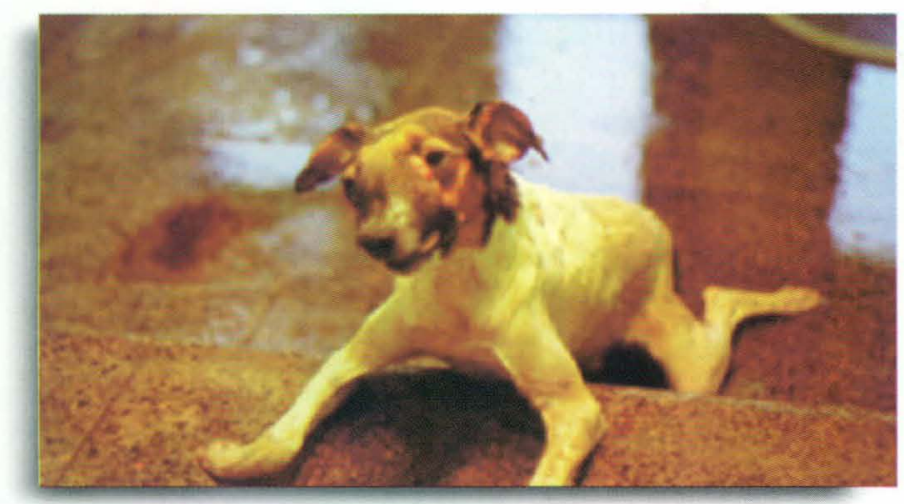

Figura 1 - Rigidez Cadavérica. Cão com tumor venéreo transmissível em seio nasal

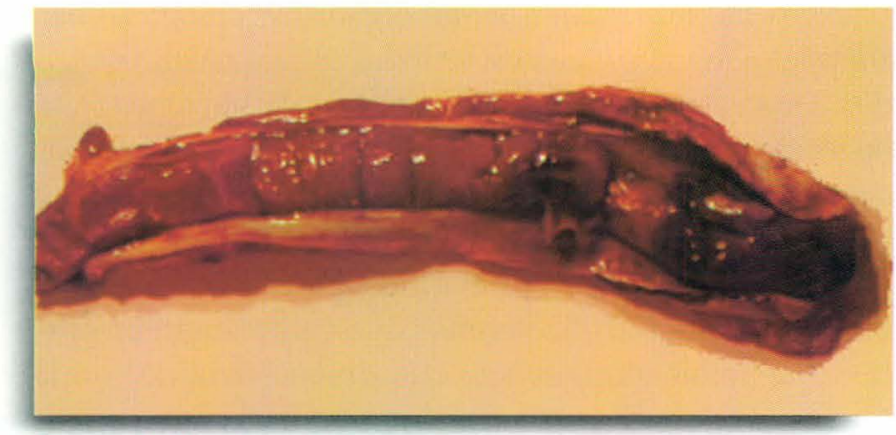

Figura 2 - Trombose. Veia jugular de eqüino

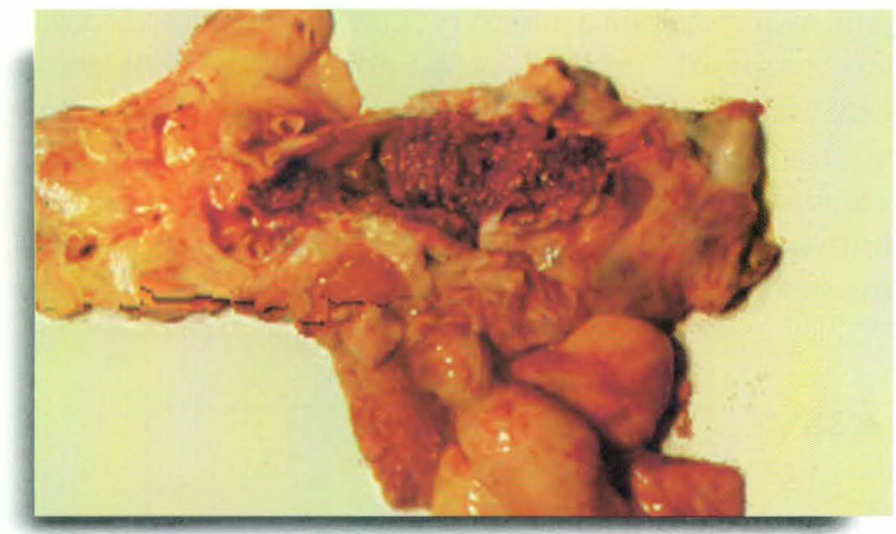

Figura 3 - Trombose. Arterite verminótica por Strongylus vulgaris em eqüino

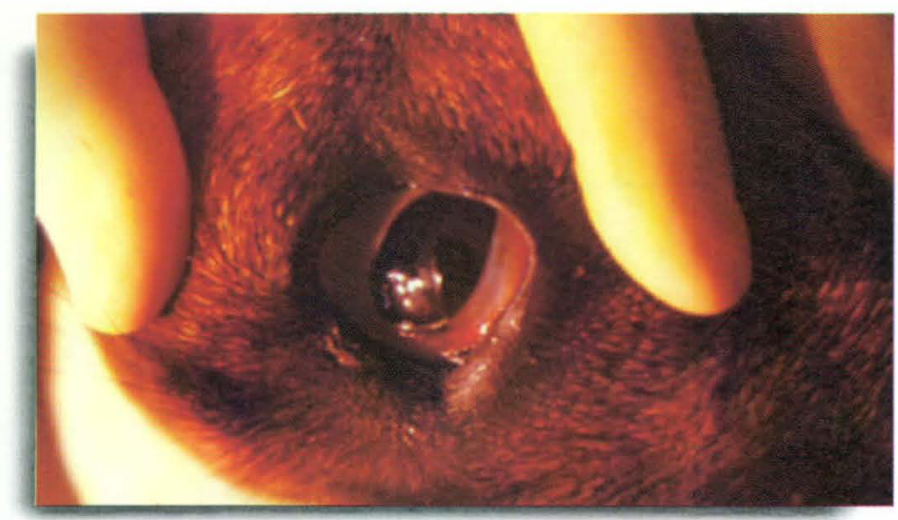

Figura 4 - Tela viscosa. Observar película sobre a córnea. Desidratação, caracterizadada pela retração do globo ocular da na cabeça, pescoço, membros anteriores, corpo, membros posteriores e finalmente na cauda. O desaparecimento desta alteração se dá na mesma ordem, facilitando assim, de maneira geral, a análise referente ao tempo da morte.

Deve-se destacar que o rigor mortis se instala e desaparece apenas uma vez, não havendo possibilidade de nova ocorrência.

Fatores relacionados com as condições mórbidas pregressas ou o tipo de morte exercem influência determinante neste processo e merecem ser destacadas; assim, de maneira geral, a rigidez cadavérica é acelerada nos casos de doenças infecciosas de curso agudo, quadros convulsivos, trabalho muscular intenso e temperatura ambiente alta.

Ao contrário, é retardada em animais caquéticos e com baixa temperatura, e no caso de doenças consuntivas ou coma de longa duração ela não ocorre ou é efêmera.

De maior relevância é o exame do coração em relação ao rigor mortis, já que como órgão muscular que é, o fenômeno instala-se rapidamente no músculo cardíaco promovendo a expulsão do sangue do seu interior, de maneira completa em relação ao ventrículo esquerdo e parcial no ventrículo direito, em virtude de sua maior capacidade e parede muscular mais fina. Assim sendo, espera-se encontrar, quando do exame macroscópico do coração, sangue coagulado no ventrículo direito e ausência de coágulos no esquerdo; no caso de encontrar-se sangue coagulado no ventrículo esquerdo, é sinal que o rigor mortis não ocorreu de maneira satisfatória e deve ser interpretado como indicativo de processos degenerativos de miocárdio.

\section{Coagulação do sangue}

A coagulação sangüínea deve ser merecedora de atenções especiais, pois trata-se de um processo que pode ocorrer tanto em vida (trombos) como no post mortem, daí a necessidade de serem estabelecidas as diferenças entre ambas, evitando-se assim erros de interpretação dos achados macroscópicos.

De forma simplificada, os coágulos podem ser classificados em cruóricos e lardáceos, sendo os primeiros compostos predominantemente pelas hemácias, possuindo uma cor vermelha. No segundo tipo predominam os leucócitos, advindo uma coloração branco amarelada, também chamados de coágulos "gordura de galinha' (chicken fat).

Nos fenômenos de coagulação post mortem, predominam os coágulos cruóricos, exceção feita nos casos 
de óbitos após longo período de pré-coma ou coma onde se verifica com freqüência a ocorrência dos coágulos lardáceos, principalmente nas câmaras cardíacas; este último dado não deve ser levado em consideração nos equídeos que mostram esta característica em um grande número de animais, sem relação direta com processos agônicos.

Ao prosector de uma necroscopia é fundamental a diferenciação entre coágulo pós morte e trombo, de forma que são apresentadas a seguir as principais diferenças entre os dois processos.

\section{Diferenças entre coágulos cruóricos e trombos}

\section{Coágulos}

Brilhantes

- Superfície regular

- Destacam-se facilmente

- Após remoção, local de adesão mostra superfície lisa.

\section{Trombos}

- Desprovidos de brilho

- Superfície irregular

- Aderidos à superfície de inserção

- Implantados sobre superfície irregular

\section{Alterações oculares}

As principais alterações que merecem destaque são: pálpebras entreabertas que ocorrem em virtude da rigidez cadavérica dos músculos palpebrais, como já visto anteriormente, os primeiros músculos a sofrerem o rigor mortis; a retração dos globos oculares em virtude dos fenômenos de desidratação ou perda de líquidos por qual passa o cadáver; a dilatação das pupilas ou midríase cadavérica em consequiência da perda do tonus muscular; a opacidade da córnea pela deposição de partículas existentes no ar e que se depositam sobre a mesma formando o que se denomina de "tela viscosa".

A morte somática de um organismo complexo não significa a morte simultânea de todas as suas células e tecidos. Desta forma, o tempo necessário para que uma célula ou tecido morra é variável dependendo das suas necessidades metabólicas o que teve grande importância para o desenvolvimento das técnicas de transplantes de órgãos.

Uma célula, ao morrer, libera potentes enzimas armazenadas em seus lisossomos que darão início ao processo denominado autólise, que desencadeia de forma gradativa a auto digestão tissular.

Este processo começa a se desenvolver algumas poucas horas após a morte (células nervosas e medula da supra-renal), portanto na fase abiótica dos fenômenos cadavéricos e prossegue até a ocorrência dos fenômenos transformativos destrutivos. A autólise, embora seja um fenômeno abiótico, é melhor classificada como destrutivo, uma vez que causa profundas alterações nas estruturas dos tecidos.

\section{SUMMARY}

The first part of a review on Tanathology where the abiotical cadaveric phenomenons is presented, and the importance of the knowledge of each one of them in the interpretation of the necropsy findings and their utility in the approached determination of the time elapsed after the death is detached.

Uniterms: Tanathology, Cadaveric phenomenons

\section{BIBLIOGRAFIA DE APOIO}

1 - ANDERSON,N.V. Veterinary gastroenterology. 2. ed. London. Lea \& Febiger, 1992. 873p.

2 - ANDRADE, Z.; BARRETTO NETTO, M.; BRITO, T.; MON-
TEnEGro, M.R. Patologia. Processos gerais. 3. ed. São Paulo, Atheneu, 1992. 263p.

3 - CARLTON, W.W. \& McGAVIN, M.D.. Thomson's speci- 
al veterinary pathology, 2. ed. St.Louis: Mosby, 1995. $654 \mathrm{p}$.

4 - CHEVILLE, N.F. Introdução à patologia veterinária. São Paulo, Manole, 1994, 556p.

5 - COTRAN,R.S.; KUMAR,V.; ROBBINS, S.L. Robbins pathologic basis of disease, 5. ed. Philadelphia, W.B.Saunders , 1994.1400p.

6 - FRANÇA, G.V. Medicina legal. Rio de Janeiro, GuanabaraKoogan, 1995, 416 p.

7 - JONES,T.C.; HUNT, R.D.; KING ,N.W. Veterinary pathology, 6. ed. Baltimore, Willians \& Wilkins, 1997.1392p.

8 - JUBB, K.V.F.; KENNEDY, P.C.; PALMER, N. Pathology of domestic animals. 4. ed. New York, Academic Press, 3 volumes.
9 - PETISCA, J.L.N. ; MONTANO, A.T. A técnica de necropsia em Medicina Veterinária. Lisboa, Luso Espanhola, 1962.

10 - RUBIN, E.; FARBER, J.L. Pathology, 2. ed. Philadelphia, J.B. Lippincott, 1998, 1578p.

11 - SILVA, O.P. Medicina legal, Rio de Janeiro, Ed.Guanabara, 1971, 293 p.

12 - TÁVERO,F. Medicina legal, 6 ed. São Paulo, Ed. Martins, 1962, $460 \mathrm{p}$.

13 - VASCONCELOS, A C. Necropsia e remessa de material para laboratório em Medicina Veterinária. Brasília, ABEAS, $1988,73 \mathrm{p}$.

14 - WINTER, H. Guia para necropsia de los ruminantes domésticos. Zaragoza, Acribia, 1969. 118 p.
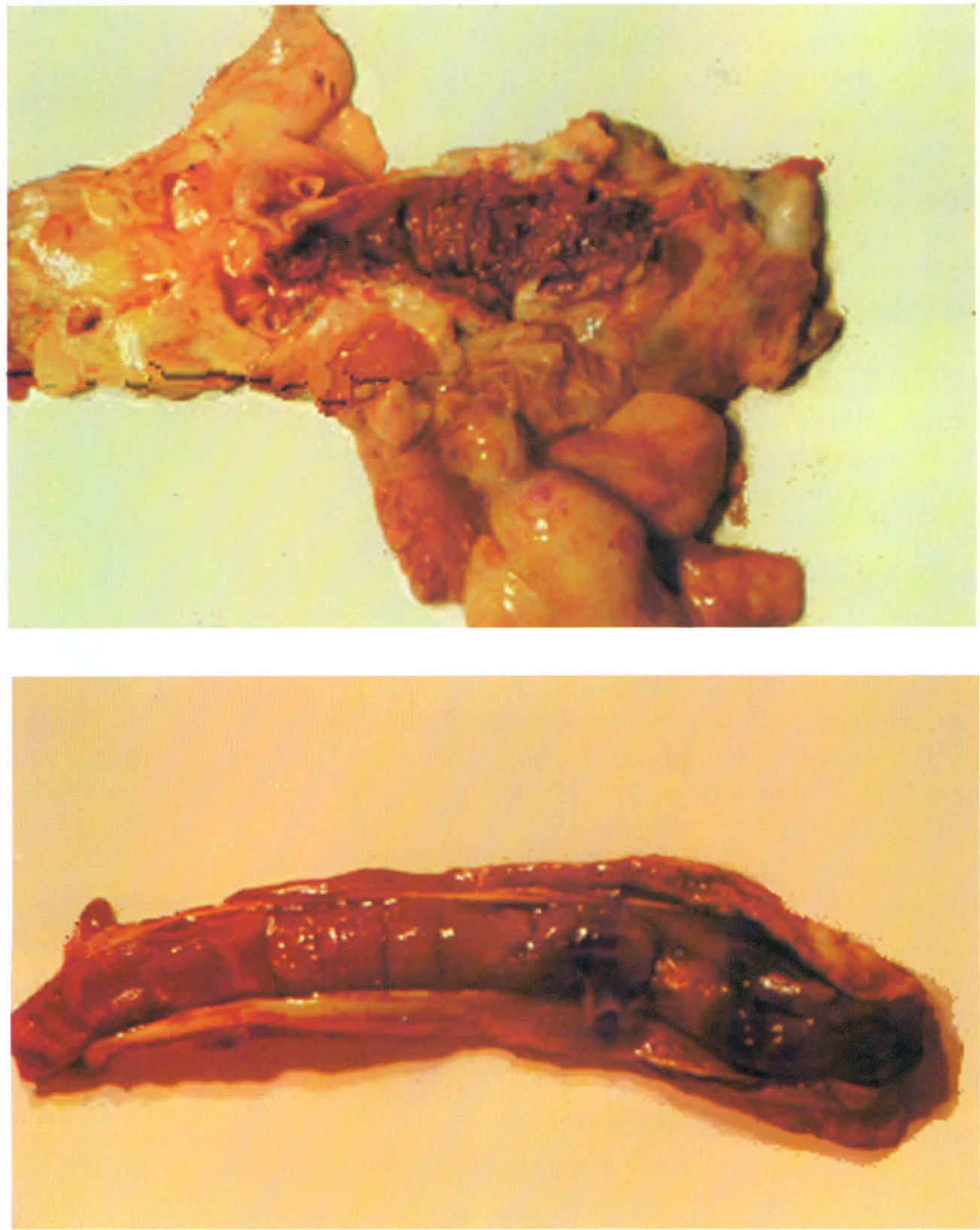